\title{
Clozapine reduced symptoms and side effects in patients who had refractory schizophrenia
}

\author{
Rosenheck $R$, Cramer J, Weichun X, et al. A comparison of clozapine and haloperidol in hospitalized patients with refractory \\ schizophrenia. N Engl J Med 1997 Sep 18;337:809-15.
}

\section{Question}

In patients who have refractory schizophrenia and frequently use inpatient services is clozapine more effective than haloperidol?

\section{Design}

12 month randomised, double blind, controlled trial.

\section{Setting}

15 Veterans Affairs medical centres in the US.

\section{Patients}

423 patients (mean age 44 y, $98 \%$ men) who had schizophrenia according to the DSM-III-R. Inclusion criteria were 30-364 days in the hospital for schizophrenia in the previous year; refractoriness; severe symptoms; and serious social dysfunction for the previous 2 years.

\section{Intervention}

Patients were allocated to haloperidol, 5 to $30 \mathrm{mg} /$ day, and benztropine mesylate, 2 to $10 \mathrm{mg} /$ day, for extrapyramidal side effects $(n=218)$ or to clozapine, 100 to $900 \mathrm{mg} /$ day, and a matching benztropine placebo $(n=205)$.

\section{Main outcome measures}

Symptoms of schizophrenia (Structured Clinical Interview for the Positive and Negative Syndrome Scale [PANSS]); quality of life ([QoL] Heinrichs-Carpenter Quality-of-Life Scale); side effects (Abnormal Involuntary Movement Scale [AIMS] for tardive dyskinesia, Barnes Akathisia Scale for restlessness, and Simpson-Angus Scale for extrapyramidal symptoms); and days in the hospital for psychiatric reasons. Costs of health care and costs to society were assessed using 1994 US dollars.

\begin{abstract}
Main results
Analysis was by intention to treat. Compliance with treatment was higher for clozapine than haloperidol (57\% v 28\%, $\mathrm{p}<0.001)$. Patients who received clozapine had 5.4\% lower symptom levels than patients who received haloperidol (PANSS score mean difference $[\mathrm{MD}] 4.5, \mathrm{p}=0.02)$. No improvement in QoL occurred over time. Compared with patients who received haloperidol, those who received clozapine had 31\% less tardive dyskinesia (AIMS score MD 1.6, $\mathrm{p}=0.005$ ), 35\% less akathisia (Barnes Akathisia Scale score MD 1.4, p <0.001), and 35\% fewer extrapyramidal symptoms (Simpson-Angus Scale score MD 1.4, $\mathrm{p}<0.001$ ) over time. Compared with haloperidol, patients who received clozapine spent 24.3 fewer days in the hospital for psychiatric reasons/year $(p=0.03)$ and had 35.7 more outpatient visits $(p=0.03)$. Compared with haloperidol, clozapine costs were higher per capita for outpatient treatment $(\$ 8473 v \$ 3474$, $\mathrm{p}<0.001)$ and for drugs $(\$ 3199 v \$ 367, \mathrm{p}<0.001)$. Costs for inpatient hospital days were lower for clozapine than haloperidol ( $\$ 45247 v \$ 53931, \mathrm{p}=0.01)$. Total per capita costs of health care and costs to society did not differ between treatments.
\end{abstract}

\section{Conclusions}

Clozapine led to greater compliance and fewer symptoms and side effects than haloperidol in patients who had refractory schizophrenia. Overall costs were similar for both drugs.

Sources of funding:Department of Veterans Affairs Health Services Research and Development Service and Sandoz Pharmaceuticals.

For correspondence: Dr R Rosenheck, Northeast Program Evaluation Center (182), VA Connecticut Healthcare System, 950 Campbell Avenue, West Haven, CT 06516, USA. Fax +1 2039373433.

\section{Commentary}

This large study by Rosenheck et al will help psychiatrists, commissioners of care, and patients. Although a trial differs from routine practice, the use of rehabilitation and case management made it more realistic. Meaningful clinical improvements in symptoms and QoL were equally common at 1 year for both treatments. Further analysis of only those who adhered to treatment, and of those who crossed over to the other treatment, showed that clozapine was more effective. This emphasises the benefits of good compliance, whichever drug is used. People tend to get better anyway; continuing with haloperidol can work in severe schizophrenia, but may have a cost to the patient, if not to the service.

Clozapine tablets cost more than haloperidol tablets but the total treatment packages do not. Moreover, clozapine was associated with fewer side effects. This probably improved compliance and, perhaps, the outcome. These fewer side effects are not usually incorporated into QoL scales or cost schedules. What price being free of akathisia? It would be interesting to know what patients think.

Should we treat refractory schizophrenia with clozapine? The results of this study make it hard to justify not doing so in patients who frequently use inpatient services. We would all like to think we use conventional antipsychotics in a more sophisticated way than a fixed dosage schedule of haloperidol allows and, increasingly, psychiatrists will consider the use of some psychotherapies. However, assertive community treatments that aim to avoid admissions, rehabilitation, and daycare services may all have different total costs for clozapine. Large unit costs may not be saved if relapses are managed out of hospital. Care for some people will cost more in the community as they get better and use services which were of no benefit to them before. With clozapine restricted to those with refractory illness, these costs will not be offset by people who are able to leave mental health services and, perhaps, return to work.

We should not ignore the current evidence, but we need to be cautious when generalising from research to practice and across mental health services. This study shows that effective treatment costs do not involve drug costs only. It also shows that we need to be more sophisticated when we discuss care with patients and administrators. Finally, it raises questions about the true costs of clozapine and other new drugs in the community.

Peter Jones, MB, MSc, PhD University of Nottingham Nottingham, UK 